\title{
Predictors of 30-Month Outcome after Perinatal Depression: Role of Proton MRS and Socioeconomic Factors
}

\author{
STEVEN P. MILLER, NANCY NEWTON, DONNA M. FERRIERO, J. COLIN PARTRIDGE, \\ DAVID V. GLIDDEN, ALISON BARNWELL, NATHANIEL A. CHUANG, \\ DANIEL B. VIGNERON, AND A. JAMES BARKOVICH
}

\begin{abstract}
Department of Neurology [S.P.M., D.M.F, A.B., A.J.B.], Department of Pediatrics [N.N., D.M.F., J.C.P., A.J.B.], Department of Epidemiology and Biostatistics [D.V.G.], Department of Radiology [N.A.C., D.B.V., A.J.B.], University of California San Francisco, San Francisco, California 94143, U.S.A.
\end{abstract}

\begin{abstract}
The objective was to determine in infants with perinatal depression whether the relative concentrations of $\mathrm{N}$-acetylaspartate and lactate in the neonatal period are associated with (1) neurodevelopmental outcome at 30 mo of age or (2) deterioration in outcome from age 12 to $30 \mathrm{mo}$; and to determine whether socioeconomic factors are associated with deterioration in outcome. Thirty-seven term neonates were prospectively studied with single-voxel proton magnetic resonance spectroscopy of the basal nuclei and intervascular boundary zones. Thirty-month outcomes were classified as normal [if Mental Development Index of the Bayley Scales of Infant Development (MDI) $>85$ and neuromotor scores (NMS) $<3 ; n=15$ ], abnormal [if MDI $\leq 85 \mathrm{and} /$ or NMS $\geq 3$ at 12 and $30 \mathrm{mo} ; n=11$ ], or deteriorated [if normal at $12 \mathrm{mo}$ and abnormal at $30 \mathrm{mo}$ (MDI $\leq 85$ or NMS $\geq 3) ; n=11]$. Thirty percent (11/37) of our cohort deteriorated between 12 and $30 \mathrm{mo}$. $\mathrm{N}$-acetylaspartate/choline decreased across the groups ordered as normal, deteriorated, and abnormal [in basal nuclei $(p \leq 0.001)$ and intervascular boundary zones $(p$ $=0.04)$ ], but was not different between the normal and deteriorated groups $(p=0.08)$. Lactate/choline similarly increased
\end{abstract}

\section{ABSTRACT}

across the groups [in basal nuclei $(p=0.01)$ and intervascular boundary zones $(p=0.05)]$. The odds of deterioration, if normal at $12 \mathrm{mo}$, increased by a factor of 5.1 ( $95 \%$ confidence interval: 1.3-19.8) with each decrease in one of four household income strata. Infants with perinatal depression are at high risk of developmental deterioration between 12 and 30 mo of age, particularly if in a lower income home or with intermediate values of cerebral metabolites on neonatal proton magnetic resonance spectroscopy. (Pediatr Res 52: 71-77, 2002)

BN, basal nuclei

Abbreviations

IBZ, intervascular boundary zones

ICN, intensive care nursery

MDI, mental development index

MR, magnetic resonance

NAA, $N$-acetylaspartate

NMS, neuromotor score

${ }^{\mathbf{1}}$ H-MRS, proton magnetic resonance spectroscopy
A number of studies have demonstrated that ${ }^{1} \mathrm{H}$-MRS can be used to predict neurodevelopmental outcome at $12 \mathrm{mo}$ in term-born infants with perinatal depression (1-3). No study to date, however, has associated relative concentrations of NAA or lactate, as measured by ${ }^{1} \mathrm{H}-\mathrm{MRS}$, with longer-term neurodevelopmental outcome. The purpose of this study was to determine, in infants with perinatal depression, (1) whether ${ }^{1} \mathrm{H}$-MRS results are associated with neurodevelopmental out-

Received July 26, 2001; accepted Jan 11, 2002.

Correspondence: A. James Barkovich, M.D., Department of Radiology, University of California, 505 Parnassus Ave., San Francisco, CA 94143-0628, U.S.A.; e-mail: jimb@radiology.ucsf.edu

Supported by the National Institutes of Health (NIH) Grant NS35902 and NIH Pediatric Clinical Research Center Grant M01-RR01271 (D.M.F., N.N., A.J.B.). S.P.M. is supported by the Canadian Institutes of Health Research Clinician Scientist Program (Phase 1) and the Glaser Pediatric Research Network Fellowship Award. come at 30 mo of age, and (2) whether the relative concentrations of NAA and lactate in the neonatal period are associated with changes in neurodevelopmental status from age $12 \mathrm{mo}$ to 30 mo. Given that socioeconomic factors impact long-term developmental outcome of ICN graduates $(4,5)$, we sought to determine the contribution of socioeconomic factors to changes in outcome at 30 mo of age in this cohort.

\section{METHODS}

We assembled a prospective cohort of term neonates with perinatal depression to study the MR predictors of neurodevelopmental outcome. This cohort, extensively described elsewhere (2), was derived from screening 5389 consecutive term neonates born in or transferred to our institution's ICN since 1994. The cohort comprises 126 infants studied with MR 
imaging (MRI) with one of the following indicators of perinatal depression: (1) umbilical artery $\mathrm{pH}<7.1$; (2) umbilical artery base deficit $>10$; or (3) 5 -min Apgar score $\leq 5$. Newborns were excluded if (1) gestational age was $<36 \mathrm{wk}$, or (2) there were suspected or confirmed congenital malformations, congenital metabolic disease, or congenital infections. The protocol was approved by the Committee on Human Research at the University of California San Francisco. Infants were studied only after voluntary informed consent was obtained from their parents.

Since the introduction of ${ }^{1} \mathrm{H}-\mathrm{MRS}$ as part of the study protocol in 1995, we have studied 91 newborns. Five of these 91 newborns have expired and 14 have been lost to follow-up. Of those studied with ${ }^{1} \mathrm{H}-\mathrm{MRS}, 61$ have completed their 12-mo follow-up and 37 of these newborns have also completed their 30-mo follow-up. This consecutive series of 37 patients who completed both the 12- and 30-mo follow-up assessments comprises the group reported in this article.

MR data. MRI and spectroscopy were done at a median of $6 \mathrm{~d}$ of life (range 2-13). The same MR scanner and techniques were used for the entire cohort. The newborns were imaged as soon as they were stable enough to be transported safely to the MR scanner and imaging time was available. MRI of the brain in all newborns included 4-mm (1-mm "gap") sagittal spinecho (SE) [500/11/2 (TR/TE/excitations)], 4-mm (1-mm "gap") axial SE (500/11/2) images, and 4-mm (2-mm "gap") axial SE (3000/60,120/1) images through the entire brain. MR abnormalities in the $\mathrm{BN}$ and frontal IBZ were scored using a system previously validated for the determination of neuromotor outcome (6). This system scores both regions on the T1 sequence and the first echo of the T2 sequence separately. Using this system, MRI abnormalities were scored in the BN as follows: $0=$ normal or isolated focal cortical infarct; $1=$ abnormal signal in thalamus; 2 = abnormal signal in thalamus and lentiform nucleus; $3=$ abnormal signal in thalamus, lentiform nucleus, and perirolandic cortex; and $4=$ more extensive involvement. Findings in the IBZ were scored as follows: $0=$ normal; $1=$ single focal infarction; $2=$ abnormal signal in anterior or posterior watershed white matter; $3=$ abnormal signal in anterior or posterior watershed cortex and white matter; $4=$ abnormal signal in both anterior and posterior watershed zones; and $5=$ more extensive cortical involvement.

Proton spectra were acquired from two separate $5-\mathrm{cm}^{3}$ voxels, one centered on the $\mathrm{BN}$, including the lentiform nucleus and thalamus (37 newborns), and the other from the frontal IBZ (36 newborns) (Fig. 1) (2). ${ }^{1} \mathrm{H}-\mathrm{MRS}$ was performed using the point-resolved spectroscopy (PRESS) technique to acquire long echo-time spectra from approximately $5.5 \mathrm{~cm}^{3}$ of tissue for both regions. The spectrum for each location was acquired using the PROBE (PROton Brain Exam, General Electric, Milwaukee, WI, U.S.A.) sequence in under $5 \mathrm{~min}$ with a TR of
A

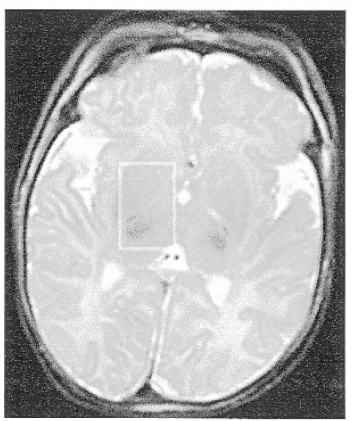

Basal Nuclei

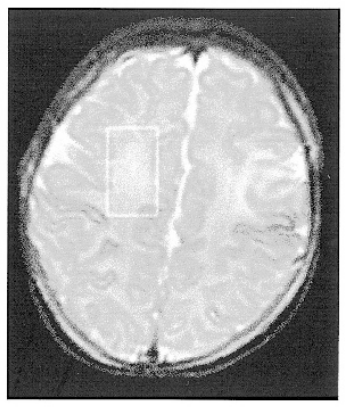

Intervascular Boundary Zone
B

Normal Outcome

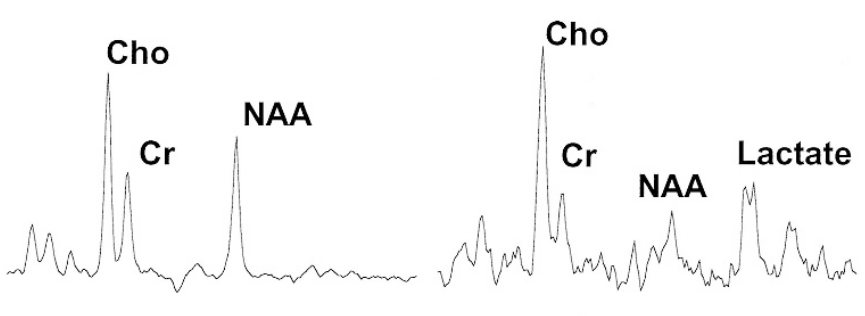

Normal Outcome

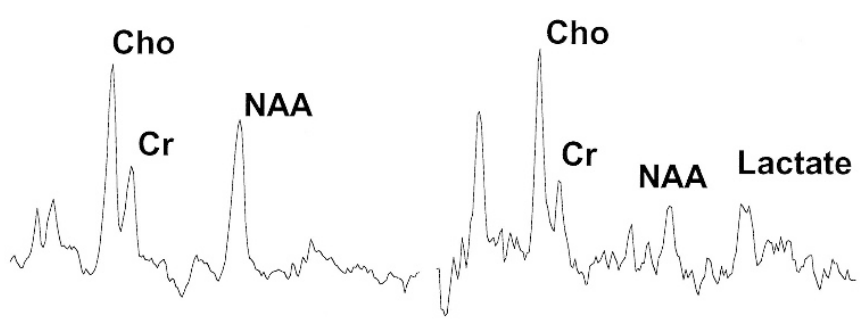

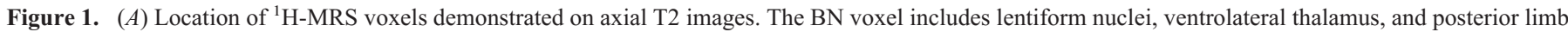

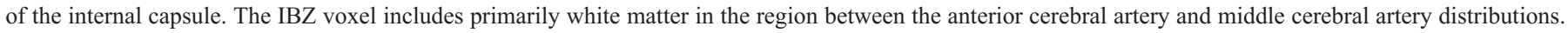

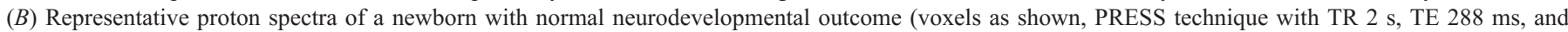

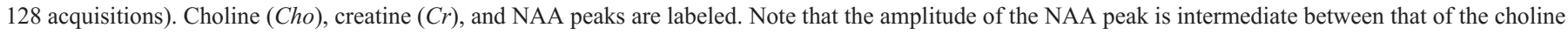

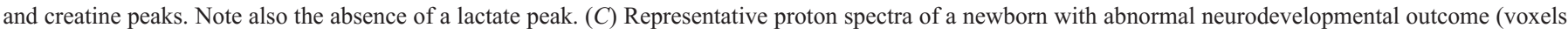

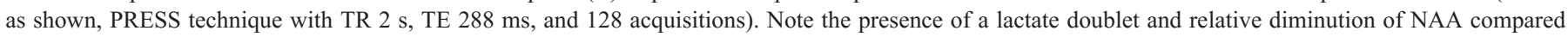
with the spectrum in $B$. 
$2 \mathrm{~s}$, a TE of $288 \mathrm{~ms}$, and a total of 128 acquisitions. The ${ }^{1} \mathrm{H}$-MRS timings and voxel localization were chosen to maximize the detection of lactate and NAA, while minimizing extracranial adipose tissue contamination of the spectra (2). The voxels used were the same in all subjects, with the hemisphere for the voxels chosen to best fit with the imaging planes. After acquisition, the ${ }^{1} \mathrm{H}-\mathrm{MRS}$ data were transferred off-line and analyzed on a SPARC Workstation (Sun Microsystems, Mountain View, CA, U.S.A.) using spectral quantitation software developed in our laboratory (2). The ${ }^{1} \mathrm{H}$-MRS data were Fourier transformed and baseline fitted. The peak areas were integrated for the choline (trimethylamine), creatine, NAA, and lactate resonances.

Neonatal condition. To quantify and summarize the clinical condition of our cohort in the neonatal period, 32 of the newborns were prospectively scored using the Score for Neonatal Acute Physiology-Perinatal Extension (SNAP-PE). SNAP-PE scores the worst physiologic derangement in each organ system during the first $24 \mathrm{~h}$ after admission, with increasing scores reflecting more severe derangement. This validated measure of illness severity is important for the prediction of neonatal mortality and was used here as an estimate of the overall clinical condition of the newborns $(7,8)$.

Developmental examinations. All patients were examined at 12 and 30 mo of age. At both assessments, cognitive development was assessed by administering the MDI of the Bayley Scales of Infant Development II (BSID II) (9). At each assessment, a pediatric neurologist blinded to the neonatal course and imaging results of the infant performed a standardized neurologic exam. The neurologist scored neuromotor outcome using a validated NMS: $0=$ normal; $1=$ abnormal tone or reflexes or primitive reflexes; $2=$ abnormal tone and reflexes; 3 = decreased power and tone or reflex abnormality; $4=$ cranial nerve involvement and any motor abnormality; and $5=$ cranial nerve involvement and spastic quadriparesis (10).

Outcome classification. Infants were classified a priori as functionally normal, if the MDI was in the normal range $(>85)$ and the NMS was $<3$ (no abnormality of motor power) at 30 mo; as abnormal, if MDI $\leq 85$ (borderline or below) and/or NMS $\geq 3$ (abnormality of motor power) at $30 \mathrm{mo}$; or as deteriorated, if normal (MDI $>85$, NMS $<3$ ) at 12 mo and abnormal (MDI $\leq 85$, NMS $\geq 3$ ) at 30 mo. The cutoff values for the NMS and the MDI were chosen to identify those children who would be targeted for rehabilitation or special educational services.

Socioeconomic condition. At the 30 -mo assessment, the primary caregiver's socioeconomic condition was assessed using the four-factor index of social status (Hollingshead A, unpublished working paper, Yale University, New Haven, CT, 1975). Total annual household income was stratified as (1) $\leq \$ 15,000$; (2) $\$ 15,000-\$ 35,000$; (3) $\$ 35,000-\$ 75,000$; and (4) $\geq \$ 75,000$. Maternal education was stratified as (1) did not complete high school; (2) completed high school (grade 12); (3) at least one year of college; (4) completed college; and (5) graduate school. Caregivers were also asked to identify whether their child was receiving any rehabilitation service (e.g. physical therapy, occupational therapy, speech therapy, developmental program).
Total annual household income was provided in 30 of 37 cases; nonresponders were distributed evenly among the groups (three normal, two deteriorated, and two abnormal). Twenty-four caretakers provided information on the highest level of maternal education achieved. Of the nonresponders, three were normal, six deteriorated, and four were abnormal. In the 21 cases where both estimates were provided, household income and maternal education were highly correlated (Spearman's $\rho=0.73, p=0.0002$ ). Given this high correlation among the two variables and the poor response rate regarding maternal education, only total annual household income was used in the analysis as a measure of the infant's socioeconomic condition.

Data analysis. Statistical analysis was performed using Stata (Stata Corporation, College Station, TX, U.S.A.). Univariate comparisons of the MDI, NMS, and MRI scores of the outcome groups were made with $t$ tests for continuous variables and the Fisher exact test for categorical variables. Change in MDI and NMS from 12 to 30 mo was determined using paired $t$ tests. To determine whether the severity of cerebral injury and the severity of neonatal systemic derangement in the outcome groups differed, ${ }^{1} \mathrm{H}-\mathrm{MRS}$ ratios and SNAP-PE scores of the groups were compared using the nonparametric test for trends across ordered groups.

Logistic regression was used to compare the following predictor variables in the normal and deteriorated groups: (1) ${ }^{1} \mathrm{H}-\mathrm{MRS}$ metabolite ratios, (2) SNAP-PE scores, and (3) total household income. This was done to determine whether deterioration from 12 to 30 mo of age could be attributed to more severe neonatal cerebral injury, more severe neonatal systemic derangement, or to socioeconomic factors.

\section{RESULTS}

Fifteen infants (40\%) were classified as normal, $11(30 \%)$ as abnormal, and $11(30 \%)$ as deteriorated (Table 1). The deterioration observed in 11 infants was primarily cognitive (Tables 1 and 2). At 12 mo of age, the normal and deteriorated groups did not differ in mean MDI $(p=0.5)$ or in the distribution of NMS $(p=0.7)$. At 30 mo of age, the normal and deteriorated groups differed in mean MDI $(p<0.00001)$, but not in the distribution of NMS $(p=0.9)$. All of the deteriorated infants had a decrease in MDI from 12 to 30 mo and one of these

Table 1. Neonatal variables and outcome scores by outcome group

\begin{tabular}{lccc}
\hline & $\begin{array}{c}\text { Normal } \\
(n=15)\end{array}$ & $\begin{array}{c}\text { Deteriorated } \\
(n=11)\end{array}$ & $\begin{array}{c}\text { Abnormal } \\
(n=11)\end{array}$ \\
\hline Male gender, $n(\%)$ & $7(54 \%)$ & $5(45 \%)$ & $6(55 \%)$ \\
Cesarean section, $n(\%)$ & $7(47 \%)$ & $2(18 \%)$ & $8(73 \%)$ \\
5-min APGAR* & $6(1-7)$ & $6(1-8)$ & $4(2-5)$ \\
Umbilical artery pH $\dagger$ & $7.1(0.1)$ & $7.1(0.1)$ & $7.0(0.1)$ \\
Neonatal seizures, $n(\%)$ & $3(20 \%)$ & $3(27 \%)$ & $8(73 \%)$ \\
SNAP-PE, mean (SD), [n] & $21.9(7.6)[14]$ & $26.7(7.1)[7]$ & $32.5(9.1)[11]$ \\
Age (d) at MRI* & $6(2-11)$ & $7(2-11)$ & $7(2-13)$ \\
12-mo MDI $\dagger$ & $97.9(13.4)$ & $95.0(6.6)$ & $65.5(17.1)$ \\
12-mo NMS $\dagger$ & $0.7(0.8)$ & $1.1(0.94)$ & $3.5(1.9)$ \\
30-mo MDI $\dagger$ & $99.3(8.8)$ & $80.1(4.0)$ & $62.5(17.5)$ \\
30-mo NMS $\dagger$ & $0.9(0.8)$ & $1.2(0.94)$ & $3.1(1.9)$ \\
\hline
\end{tabular}

$*$ Median (range); $\uparrow$ mean (SD). 
Table 2. MDI and NMS scores of individual patients in the deteriorated group

\begin{tabular}{rcccc}
\hline $\begin{array}{c}\text { Patient } \\
\text { no. }\end{array}$ & $\begin{array}{c}12-\text { mo } \\
\text { MDI }\end{array}$ & $\begin{array}{c}12-\text { mo } \\
\text { NMS }\end{array}$ & $\begin{array}{c}\text { 30-mo } \\
\text { MDI }\end{array}$ & $\begin{array}{c}30 \text {-mo } \\
\text { NMS }\end{array}$ \\
\hline 1 & 107 & 3 & 85 & 1 \\
2 & 105 & 1 & 77 & 0 \\
3 & 102 & 1 & 85 & 1 \\
4 & 95 & 1 & 75 & 1 \\
5 & 93 & 1 & 77 & 2 \\
6 & 93 & 2 & 83 & 3 \\
7 & 92 & 0 & 77 & 0 \\
8 & 90 & 0 & 75 & 2 \\
9 & 90 & 1 & 81 & 0 \\
10 & 90 & 0 & 83 & 2 \\
11 & 88 & 2 & 84 & 1 \\
\hline
\end{tabular}

children also had deterioration in NMS from 2 to 3. The mean MDI decreased only in the deteriorated group $(p<0.00001)$, and did not change in the other two groups (both $p>0.5$ ).

MRI scores were distributed differently in the three groups on the T2-weighted sequences in the $\mathrm{BN}(p=0.01)$ and IBZ $(p=0.03)$, with more severe abnormalities in the abnormal group (Table 3 ). The T1 scores did not differ among the three groups in the $\mathrm{BN}(p=0.07)$ or IBZ $(p=0.3)$. The MRI scores were not different in the normal and deteriorated groups in the $\mathrm{BN}$ or IBZ (all $p>0.2$ ) (Table 3 ).

NAA/choline differed among the three groups in $\mathrm{BN}(p \leq$ $0.001)$ and IBZ $(p=0.04)$, with lowest values in the abnormal group and highest values in the normal group (Table 4 , and Figs. 1 and 2). Lactate/choline differed among the three groups in $\mathrm{BN}(p=0.01)$ and IBZ $(p=0.05)$, with highest values in the abnormal and lowest values in the normal group (Figs. 1 and 2). Similarly, SNAP-PE differed across the three outcome groups, with highest scores in the abnormal group and lowest scores in the normal group $(p=0.01)$ (Fig. 3).

Table 3. MRI scores on $T 1$ and T2 sequences compared by outcome group

\begin{tabular}{|c|c|c|c|c|c|c|}
\hline Sequence & Region & Score & $\begin{array}{l}\text { Normal } \\
(n=15)\end{array}$ & $\begin{array}{l}\text { Deteriorated } \\
(n=11)\end{array}$ & $\begin{array}{c}\text { Abnormal } \\
(n=11)\end{array}$ & $p$ Value \\
\hline \multirow[t]{11}{*}{$\mathrm{T} 1$} & \multirow[t]{5}{*}{$\mathrm{BN}$} & 0 & 10 & 7 & 3 & \multirow[t]{5}{*}{0.07} \\
\hline & & 1 & 0 & 1 & 3 & \\
\hline & & 2 & 3 & 1 & 0 & \\
\hline & & 3 & 2 & 2 & 3 & \\
\hline & & 4 & 0 & 0 & 2 & \\
\hline & \multirow[t]{6}{*}{ IBZ } & 0 & 12 & 10 & 5 & \multirow[t]{6}{*}{0.3} \\
\hline & & 1 & 1 & 1 & 1 & \\
\hline & & 2 & 1 & 0 & 1 & \\
\hline & & 3 & 1 & 0 & 1 & \\
\hline & & 4 & 0 & 0 & 1 & \\
\hline & & 5 & 0 & 0 & 2 & \\
\hline \multirow[t]{11}{*}{$\mathrm{T} 2$} & \multirow[t]{5}{*}{$\mathrm{BN}$} & 0 & 13 & 9 & 3 & \multirow[t]{5}{*}{0.01} \\
\hline & & 1 & 0 & 0 & 1 & \\
\hline & & 2 & 1 & 1 & 2 & \\
\hline & & 3 & 1 & 0 & 1 & \\
\hline & & 4 & 0 & 1 & 4 & \\
\hline & \multirow[t]{6}{*}{ IBZ } & 0 & 5 & 3 & 1 & \multirow[t]{6}{*}{0.03} \\
\hline & & 1 & 0 & 1 & 0 & \\
\hline & & 2 & 3 & 0 & 1 & \\
\hline & & 3 & 2 & 0 & 0 & \\
\hline & & 4 & 5 & 7 & 5 & \\
\hline & & 5 & 0 & 0 & 4 & \\
\hline
\end{tabular}

Table 4. ${ }^{1} H-M R S$ variables expressed as metabolite ratios by outcome group

\begin{tabular}{llccc}
\hline & Normal & Deteriorated & Abnormal & $p$ Value \\
\hline BN NAA/Cho & $0.762(0.10)$ & $0.675(0.13)$ & $0.615(0.10)$ & $\leq 0.001$ \\
BN lactate/Cho & $0.078(0.07)$ & $0.112(0.07)$ & $0.280(0.26)$ & 0.01 \\
IBZ NAA/Cho & $0.780(0.13)$ & $0.728(0.17)$ & $0.629(0.17)$ & 0.04 \\
IBZ lactate/Cho & $0.11(0.08)$ & $0.120(0.07)$ & $0.296(0.29)$ & 0.05 \\
\hline
\end{tabular}

Numbers given as mean (SD). Cho, choline.

In comparisons aimed at distinguishing the normal group from the deteriorated group based on neonatal predictor variables, there was no significant difference, but a trend for lower BN NAA/choline in the deteriorated group compared with the normal group [odds ratio 663.7 (95\% confidence interval [CI]: $0.38-1,161,336), p=0.08]$. As BN NAA/choline was most strongly associated with outcome status when comparing the three groups, only this ${ }^{1} \mathrm{H}-\mathrm{MRS}$ variable was tested to distinguish the normal group from the deteriorated group.

SNAP-PE, the other neonatal predictor variable, was not significantly different between the normal group and the deteriorated group [odds ratio 0.91 (95\% CI: $0.79-1.04), p=$ $0.18]$.

To determine whether deterioration is associated with socioeconomic factors, we compared the household income of the normal and deteriorated groups using logistic regression (Table 5). The odds of deterioration, if normal at $12 \mathrm{mo}$, increased by a factor of $5.1(95 \%$ CI: $1.3-19.8 ; p=0.02)$, with each decrease in one of four household income strata $(n=21)$. To determine whether the effect of household income on the odds of deterioration is independent of $\mathrm{BN} \mathrm{NAA} /$ choline, a multivariate logistic regression model was used. The results of this model did not differ meaningfully from the univariate analysis. The odds of deterioration, if normal at 12 mo, increased by a factor of 5.1 (95\% CI: $1.3-20.3 ; p=0.02)$ with each decrease in one of four household income strata, whereas lower basal nuclei NAA/choline was not significantly associated with deterioration [odds ratio 17.3 (95\% CI: 0.0009-319548), $p=$ 0.57]. Given the strong association of household income with normal and deteriorated outcomes, the lack of meaningful univariate association with SNAP-PE in these groups, and our sample size, SNAP-PE was not included in the multivariate regression model.

Only one deteriorated infant (patient 11 in Table 2) had a decline in MDI that was possibly within the expected error of the test. This infant was in the income group $\$ 35,000-\$ 75,000$, and removing him from the analysis did not significantly alter the results. Of the 15 normal infants, two had improved from abnormal at 12 mo of age. One of these infants, with an MDI of 82 and NMS of 0 at $12 \mathrm{mo}$, had an annual household income $\geq \$ 75,000$, and the other, with an MDI of 74 and NMS of 0 at $12 \mathrm{mo}$, had an annual household income between $\$ 35,000$ and $\$ 75,000$.

At 30 mo of age, eight infants in the abnormal group, one infant in the normal group, and none in the deteriorated group were receiving rehabilitation therapy. 
A

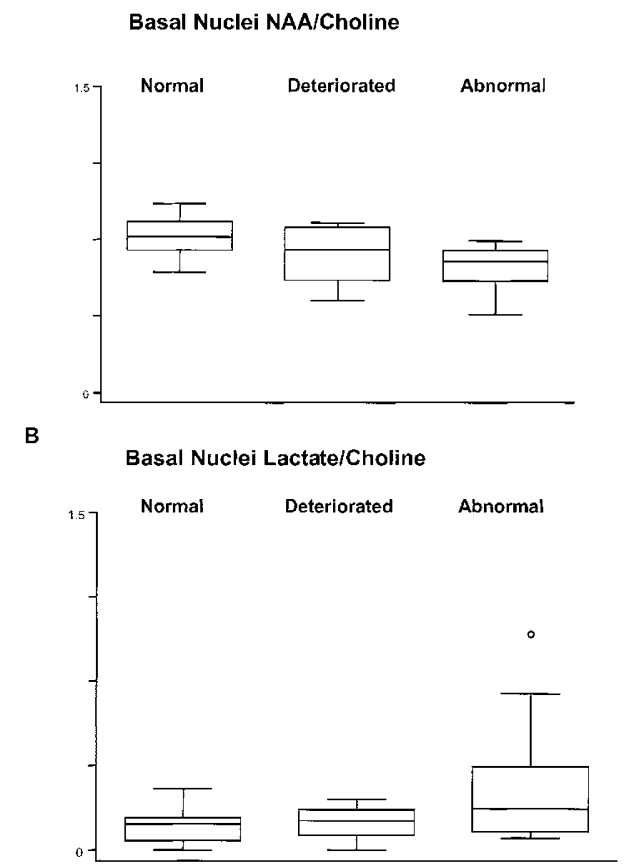

C
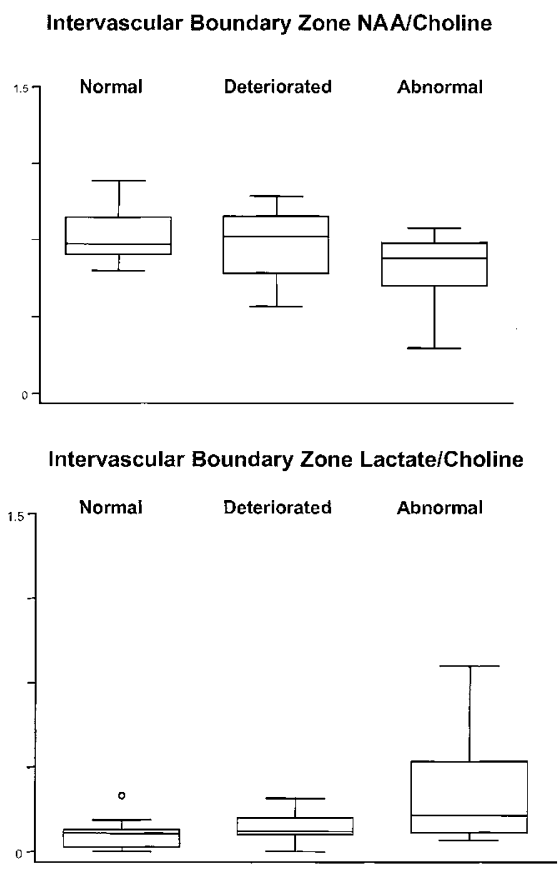

Figure 2. Box plots of cerebral metabolites by outcome group. $(A)$ BN NAA/choline differed among the three groups with lowest values in the abnormal group and highest values in the normal group $(p \leq 0.001)$. (B) BN lactate/choline differed among the three groups with highest values in the abnormal and lowest values in the normal group $(p=0.01)$. (C) IBZ NAA/choline differed among the three groups with lowest values in the abnormal group and highest values in the normal group $(p=0.04)$. (D) IBZ lactate/choline differed among the three groups with highest values in the abnormal and lowest values in the normal group $(p=0.05)$.

SNAP-PE

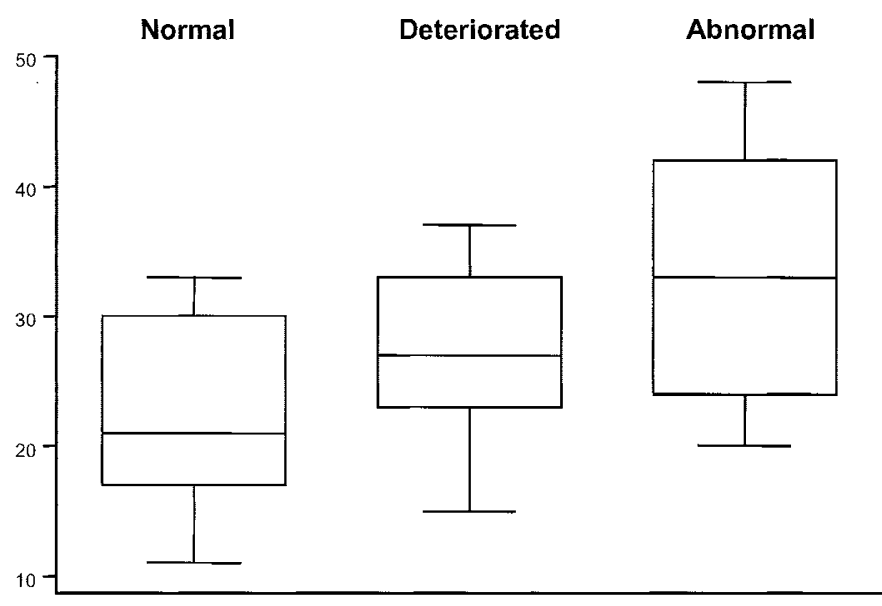

Figure 3. Box plot of SNAP-PE by outcome group. SNAP-PE differed among the three groups with highest scores in the abnormal group and lowest scores in the normal group $(p=0.01)$.

\section{DISCUSSION}

After perinatal depression in term newborns, the relative cerebral concentrations of NAA and lactate are significantly associated with outcome at $30 \mathrm{mo}$ of age. This is consistent with the observation by this group and others that abnormalities of lactate and, more variably, NAA are associated with neurodevelopmental outcome at 12 mo of age $(1,2,11-16)$, although this association was not found by others. Decreases and increases in NAA reflect neuronal integrity (17-20). As
Table 5. Total household income strata by outcome group

\begin{tabular}{lccc}
\hline No. per strata & Normal & Deteriorated & Abnormal \\
\hline$\leq \$ 15,000$ & 1 & 3 & 3 \\
$\$ 15,000-\$ 35,000$ & 0 & 3 & 2 \\
$\$ 35,000-\$ 75,000$ & 4 & 3 & 2 \\
$\geq \$ 75,000$ & 7 & 0 & 2 \\
\hline
\end{tabular}

diminished NAA/choline after perinatal depression was most strongly associated with outcome at $30 \mathrm{mo}$ of age, our findings suggest that abnormality of neuronal integrity is the most important neonatal predictor of 30-mo outcome.

We have previously reported in this cohort that the most consistent abnormality associated with neurodevelopmental impairment at 12 mo of age was the presence of a lactate peak (2). Persistent increase in lactate after birth asphyxia ( $>1 \mathrm{mo})$ may be seen in infants with abnormal neurodevelopmental outcome at 12 mo of age (21). Abnormalities of lactate reflect an ongoing metabolic disturbance (e.g. secondary to hypoxicischemic injury), or the presence of inflammatory cells (19, 22). Lactate may reflect more acute metabolic stress and, although more strongly associated with 12-mo outcome than NAA, may be less important for the prediction of longer-term neurodevelopmental outcome. Another factor may be the age of the patient at the time of the ${ }^{1} \mathrm{H}-\mathrm{MRS}$ (2). Our experience in human newborns (unreported data) and that of others in neonatal piglets (23) suggests that, after peaking during the second or third day, the size of the lactate peak diminishes during the first 2 wk after birth, and may become normal; thus, patients studied after the age of $3 \mathrm{~d}$ may have deceptively low lactate levels. In contrast, NAA concentration diminishes during the first few days after injury and thereafter remains lower than 
normal. We speculate that the fact that our patients were studied at a median age of $6 \mathrm{~d}$ may explain the increased sensitivity of the NAA measurements.

The deterioration in cognitive outcome is closely associated with lower socioeconomic condition, even when controlling for the severity of neuronal injury as measured by NAA/ choline. Criteria available in the neonatal period (lower NAA/ choline, more severe structural brain injury on MRI, or more severe systemic derangement) or at 12 mo of age (lower NMS) could not adequately predict later neurodevelopmental deterioration in infancy. Developmental disabilities in ICN graduates, including term infants with hypoxic-ischemic encephalopathy, have been associated with sociodemographic variables (poverty, race, maternal education, and gender) by several other investigators $(4,5,24)$. These variables seem to have greatest effects on mild educational disabilities (25). In our abnormal group, the group with the most severe developmental disabilities, income strata were evenly distributed. This is consistent with the previous observation that severe developmental impairments are more closely associated with perinatal factors (25).

The group of most clinical concern in our cohort was those infants who were classified as normal at $12 \mathrm{mo}$ of age who were later classified as abnormal. It is unlikely that this observation is an artifact of the test procedures. The MDI of the BSID is a stable measure of infant development in high-risk ICN survivors (26). Others have demonstrated that repeated assessment with the BSID did not bias the MDI, and that scores at 4 mo and 28 mo with repeated assessment were equivalent (27). This "repeated assessment" bias would not explain our findings, as the direction of this bias would be expected to normalize the scores of impaired infants on follow-up, thereby reducing any apparent "deterioration." An alternative explanation for the observed deterioration is that abnormal cognition became apparent only at 30 mo of age in the deteriorated group. Although the MDI at 30 mo is more enriched in verbal items than at $12 \mathrm{mo}$, we would not expect "deterioration" in only a subset of our cohort. Also, as the MR scores did not differ in the normal and deteriorated groups in the BN or IBZ, it is unlikely that the deterioration was due to late manifestations of frontal white-matter injury where impaired cognition with relatively preserved motor function would be expected.

The relationship between socioeconomic status and neurodevelopmental outcome is multifaceted and may relate, at least in part, to environmental stimulation and access to rehabilitation therapy. No infants in the deteriorated group were receiving rehabilitation therapy at $30 \mathrm{mo}$ of age. The importance of recognizing the group of children at high risk of deterioration after 12 mo of age is underscored by the potential gains of early developmental intervention in those children from a lower socioeconomic environment (28). These interventions, as demonstrated in low-birth-weight preterm children, may be most effective in improving developmental outcomes in those born to mothers with high school education or less (28). In term small-for-gestational-age infants and preterm infants, higher maternal language skills, a positive home environment, and attendance at preschool were associated with a significant increase in the mean intelligence quotient (29). The negative effects of low socioeconomic status may overshadow the impact of pre- or perinatal hypoxic-ischemic injury in those children with mild to moderate impairments.

After perinatal depression in term newborns, normal neurodevelopment at $12 \mathrm{mo}$ of age does not ensure a normal long-term outcome. Overall, given the prevalence and implications of low socioeconomic status, it is incumbent on the clinician to identify these high-risk infants so that they continue to be followed after 12 mo of age and are targeted for appropriate developmental services.

Acknowledgments. The authors thank Amy Ferrer Rogers, project manager, Faith Allen, data manager, and the neonatal nurses of the Pediatric Clinical Research Center for their expertise.

\section{REFERENCES}

1. Amess PN, Penrice J, Wylezinska M, Lorek A, Townsend J, Wyatt JS, Amiel-Tison C, Cady EB, Stewart A 1999 Early brain proton magnetic resonance spectroscopy and neonatal neurology related to neurodevelopmental outcome at 1 year in term infants after presumed hypoxic-ischaemic brain injury. Dev Med Child Neurol 41:436-445

2. Barkovich AJ, Baranski K, Vigneron D, Partridge JC, Hallam DK, Hajnal BL, Ferriero DM 1999 Proton MR spectroscopy for the evaluation of brain injury in asphyxiated, term neonates. AJNR Am J Neuroradiol 20:1399-1405

3. Holshouser BA, Ashwal S, Luh GY, Shu S, Kahlon S, Auld KL, Tomasi LG, Perkin RM, Hinshaw Jr DB 1997 Proton MR spectroscopy after acute central nervous system injury: outcome prediction in neonates, infants, and children. Radiology 202:487-496

4. Piecuch RE, Leonard CH, Cooper BA, Sehring SA 1997 Outcome of extremely low birth weight infants (500 to 999 grams) over a 12-year period. Pediatrics 100:633639

5. Resnick MB, Gomatam SV, Carter RL, Ariet M, Roth J, Kilgore KL, Bucciarelli RL, Mahan CS, Curran JS, Eitzman DV 1998 Educational disabilities of neonatal intensive care graduates. Pediatrics 102:308-314

6. Barkovich AJ, Hajnal BL, Vigneron D, Sola A, Partridge JC, Allen F, Ferriero DM 1998 Prediction of neuromotor outcome in perinatal asphyxia: evaluation of MR scoring systems. AJNR Am J Neuroradiol 19:143-149

7. Richardson DK, Phibbs CS, Gray JE, McCormick MC, Workman-Daniels K, Goldmann DA 1993 Birth weight and illness severity: independent predictors of neonatal mortality. Pediatrics 91:969-975

8. Richardson DK, Gray JE, McCormick MC, Workman K, Goldmann DA 1993 Score for Neonatal Acute Physiology: a physiologic severity index for neonatal intensive care. Pediatrics 91:617-623

9. Bayley N 1993 The Bayley Scales of Infant Development II. New York Psychological Corporation, New York

10. Hajnal BL, Sahebkar-Moghaddam F, Barnwell AJ, Barkovich AJ, Ferriero DM 1999 Early prediction of neurologic outcome after perinatal depression. Pediatr Neurol 21:788-793

11. Ashwal S, Holshouser BA, Tomasi LG, Shu S, Perkin RM, Nystrom GA, Hinshaw $\mathrm{DB}$, Jr $1997{ }^{1} \mathrm{H}$-magnetic resonance spectroscopy-determined cerebral lactate and poor neurological outcomes in children with central nervous system disease. Ann Neurol 41:470-481

12. Hanrahan JD, Sargentoni J, Azzopardi D, Manji K, Cowan FM, Rutherford MA, Cox IJ, Bell JD, Bryant DJ, Edwards AD 1996 Cerebral metabolism within 18 hours of birth asphyxia: a proton magnetic resonance spectroscopy study. Pediatr Res 39:584590

13. Holshouser BA, Ashwal S, Shu S, Hinshaw Jr DB 2000 Proton MR spectroscopy in children with acute brain injury: comparison of short and long echo time acquisitions. J Magn Reson Imaging 11:9-19

14. Shu SK, Ashwal S, Holshouser BA, Nystrom G, Hinshaw Jr DB 1997 Prognostic value of ${ }^{1} \mathrm{H}-\mathrm{MRS}$ in perinatal CNS insults. Pediatr Neurol 17:309-318

15. Groenendaal F, Veenhoven RH, van der Grond J, Jansen GH, Witkamp TD, de Vries LS 1994 Cerebral lactate and N-acetyl-aspartate/choline ratios in asphyxiated fullterm neonates demonstrated in vivo using proton magnetic resonance spectroscopy. Pediatr Res 35:148-151

16. Penrice J, Cady EB, Lorek A, Wylezinska M, Amess PN, Aldridge RF, Stewart A, Wyatt JS, Reynolds EO 1996 Proton magnetic resonance spectroscopy of the brain in normal preterm and term infants, and early changes after perinatal hypoxia-ischemia. Pediatr Res 40:6-14

17. Hüppi PS, Fusch C, Boesch C, Burri R, Bossi E, Amato M, Herschkowitz N 1995 Regional metabolic assessment of human brain during development by proton magnetic resonance spectroscopy in vivo and by high-performance liquid chromatography/gas chromatography in autopsy tissue. Pediatr Res 37:145-150

18. Kreis R, Ernst T, Ross BD 1993 Development of the human brain: in vivo quantification of metabolite and water content with proton magnetic resonance spectroscopy. Magn Reson Med 30:424-437 
19. Novotny E, Ashwal S, Shevell M 1998 Proton magnetic resonance spectroscopy: an emerging technology in pediatric neurology research. Pediatr Res 44:1-10

20. Toft PB, Christiansen P, Pryds O, Lou HC, Henriksen O 1994 T1, T2, and concentrations of brain metabolites in neonates and adolescents estimated with H-1 MR spectroscopy. J Magn Reson Imaging 4:1-5

21. Hanrahan JD, Cox IJ, Edwards AD, Cowan FM, Sargentoni J, Bell JD, Bryant DJ, Rutherford MA, Azzopardi D 1998 Persistent increases in cerebral lactate concentration after birth asphyxia. Pediatr Res 44:304-311

22. Petroff OA, Graham GD, Blamire AM, al-Rayess M, Rothman DL, Fayad PB, Brass LM, Shulman RG, Prichard JW 1992 Spectroscopic imaging of stroke in humans: histopathology correlates of spectral changes. Neurology 42:1349-1354

23. Penrice J, Lorek A, Cady EB, Amess PN, Wylezinska M, Cooper CE, D'Souza P, Brown GC, Kirkbride V, Edwards AD, Wyatt JS, Reynolds EO 1997 Proton magnetic resonance spectroscopy of the brain during acute hypoxia-ischemia and delayed cerebral energy failure in the newborn piglet. Pediatr Res 41:795-802

24. Robertson C, Finer N 1985 Term infants with hypoxic-ischemic encephalopathy: outcome at 3.5 years. Dev Med Child Neurol 27:473-484
25. Resnick MB, Gueorguieva RV, Carter RL, Ariet M, Sun Y, Roth J, Bucciarelli RL, Curran JS, Mahan CS 1999 The impact of low birth weight, perinatal conditions, and sociodemographic factors on educational outcome in kindergarten. Pediatrics 104:e 74

26. Crowe TK, Deitz JC, Bennett FC 1987 The relationship between the Bayley Scales of Infant Development and preschool gross motor and cognitive performance. Am J Occup Ther 41:374-378

27. Haskins R, Ramey CT, Stedman DJ, Blacher-Dixon J, Pierce JE 1978 Effects of repeated assessment on standardized test performance by infants. Am J Ment Defic 83:233-239

28. Brooks-Gunn J, Gross RT, Kraemer HC, Spiker D, Shapiro S 1992 Enhancing the cognitive outcomes of low birth weight, premature infants: for whom is the intervention most effective? Pediatrics 89:1209-1215

29. Goldenberg RL, DuBard MB, Cliver SP, Nelson KG, Blankson K, Ramey SL, Herman A 1996 Pregnancy outcome and intelligence at age five years. Am J Obstet Gynecol 175:1511-1515 